\title{
Prešernovi soneti in pesniška samorefleksija
}

\author{
MARKO JUVAN \\ Inštitut za slovensko literaturo in literarne vede, Znanstveno-raziskovalni center SAZU \\ Novi trg 5, SI-1000 Ljubljana, Slovenija \\ E-mail: marko.juvan@guest.arnes.si
}

\begin{abstract}
France Prešeren made the sonnet fashionable in Slovenian literature as a representative poetic form and at the same time he revived it as a storehouse of cultural functions the influence of which could be felt up to postmodernism. Prešeren armed with the aesthetic postulate of the Schlegel brothers considered the sonnet a poetical form capable of cultivating the Slovenian poetical language and in this way raising it to the canons of classical and modern literature. In the time of Romanticism poetics belonged to the fundamental values and therefore became an integral part in discussions concerning the questions of poetic creation. Prešeren wrote a lot of poems whose main topic is self-reflexion, eg. his sonnets with the most important one in them: The Wreath of Sonnets. Prešeren in these sonnets grouped the contexts, goals, structures and situations pointing out their critical reception, highlighting his own modern Petrarcism. He gave reasons for his choice of style, topic and language, showed the difference between pragmatic and poetic manifestation, revealed the common roots of his personal life and his poems (making a clearcut difference between the biographical and poetical ego) mythicized his own poetic and national mission.

Finally we outline the developing stages of Prešeren's autoreflexive sonnets connected with him in an intertextual way in the time of modernism and postmodernism.
\end{abstract}

Key-words: Prešeren, sonnet, poetic self-reflection, romanticism, intertextuality, Slovene literature.

V slovenski literarni zgodovini se je utrdila teza, da je pesništvo Franceta Prešerna zaznamovala romantično-klasična poetika bratov Schlegel. To še posebej velja za estetska ozadja, na katerih je Prešeren na začetku 1830. let v slovenski literaturi uveljavljal sonet. ${ }^{1} \mathrm{Ob}$ nasvetih in publicistični podpori prijatelja Matija Čopa, svetovljansko razgledanega filologa, kritika, teoretika in literarnega zgodovinarja, je namreč vpeljal sonet zavestno in programsko, in to z oktavo, tercino, gloso in gazelo vred. Pomenil mu je prestižno romansko obliko, izvirajočo iz poznosrednjeveške in renesančne klasike. Kot takšen naj bi sonet pomagal zasnovati slovensko književnost - v tisočletju po Brižinskih spomenikih povečini nabožno kot sodobno in avtonomno leposlovje. Takšna literatura bi morala biti blizu izobražencem, odprta $\mathrm{v}$ svetovno književnost in primerljiva $\mathrm{z}$ merili mednarodnega kanona. V duhu estetske teorije Friedricha in Augusta Wilhelma Schlegla naj bi

${ }^{1}$ Po podatkih J. Pogačnika (1997: 424-427) je prvi sonet v slovenščini prevod španskega besedila Suspiria S. Francisci Xaverii v zbirki pridig (Conciones iuxta libellum Exercitiorum S. P. Ignatii (1734) Jerneja Basarja; do prvega izvirnega slovenskega soneta (Janez VESEL-KoseSKI, Potažba, Laibacher Wochenblatt, 1818) so v ljubljanski periodiki po 1. 1800 izšli še en nemški in trije italijanski soneti. 
sonet kot urejena in izrazno zahtevna oblika prispeval še k izrazno-oblikovni bogatitvi in kultiviranju slovenskega knjižnega in pesniškega jezika (prim. Paternu 1994: 9, 48-61; Pretnar 1993: 138).

Ena od odločilnih strategij za oblikovanje novega standarda avtonomne pesniške umetnosti v tedanji Kranjski je bila pri Prešernu bogata medbesedilnost, citatnost. Z njo je svoja besedila priključil na evropsko literarno klasiko; doživljal jo je kot živi sistem kulturnega spomina, temelječ na kontinuiteti antičnega, srednjeveškega in modernega izročila. Takšen pesniški univerzalizem ni bil nič izjemnega tudi v drugih evropskih romantikah. Mnoge od avtorjev, motivov, podob, figur, kompozicijskih shem, literarnih in neliterarnih del, na katere se je s citatnim sklicevanjem, aluzijami, parafrazami, variacijami in emulacijami priključeval Prešeren, so cenili in si jih prisvajali tudi drugi pesniki ali esteti na prehodu iz 18. v 19. stoletje. ${ }^{2}$ Prešeren je svoje afiliacije na Homerja, Vergila, rimske erotične elegike, Danteja, Petrarko, Tassa in druge renesančne mojstre, pa tudi na Bürgerja ali Augusta Wilhelma Schlegla razvidno zaznamoval. Svoje bralce je nanje opozarjal z aluzijami na značilne dogodke iz pisateljskih biografij in prepoznavne topose iz njihovih del; z življenjem in deli klasikov je vzporejal svoje bivanje in pesnjenje. S takšnim udomačevanjem evropske klasike je Prešeren obarval zlasti svoje sonete. Sonet pa je bil žanr, ki ga je sam izbral za glavno obliko tistega dela svojega opusa, ki ga je - v nasprotju z bolj poljudnimi ,pesmimi” - uvrščal v visoko, romantično ,poezijo”. Čeprav slovenski izobraženi bralec ni bil ravno vajen pesniške zvrsti slovenščine, ${ }^{3}$ je lahko brez večjih težav opazil, kako Prešeren emulira Petrarko in kod romantično obnovljenega petrarkizma.

Emulacija kot tekmovalna vrsta imitacije klasikov, stremeča $\mathrm{k}$ izvirnemu preseganju starih vzorov, je vsaj do sredine 30. let vplivala na Prešernovo medbesedilno razmerje $\mathrm{z}$ italijanskim mojstrom soneta. Prešeren je svojo emulacijo Petrarke v samorefleksivnem sonetu Sanjalo se mi je, de v svetem raji (Poezije 1847) duhovito in slikovito razkril. To je storil z motivom, ki funkcionira kot mise en abyme svojega lastnega ustvarjalnega postopka. Gre za alegorično podobo rajskega tehtanja umetniške teže mojstrove in učenčeve poezije oziroma primerjanje kreposti njunih pesniških izvoljenk. Prešernovo razmerje s Petrarkovim žanrskim prototipom soneta je bilo vse od Stritarjevega eseja iz leta 1866, prelomnega za proces pesnikove kanonizacije, deležno posebne pozornosti. ${ }^{4}$ Literarni zgodovinarji

2 Prim. helenofilstvo številnih predromantikov in romantikov (Winckelmanna, Goetheja, Schillerja, F. Schlegla, Hölderlina, Keatsa, Chéniera) ter zgodovinskotipološko razumevanje pojma romantika pri Thomasu Wartonu, Friedrichu Bouterweku in A. W. Schleglu; to je zajemalo dela Danteja, Petrarke, Ariosta, Tassa, Shakespeara in Cervantesa (WeLLEK 1963: 131-137, 163-165).

${ }^{3}$ PATERNU (1994: 33) piše o skromni tradiciji slovenske umetne, zlasti ucene poezije; zacenja se šele proti koncu 18. stoletja s Pisanicami in pesništvom Antonom Feliksom Devom.

${ }^{4}$ STRITAR (1969: 28, 30, 38-44) se je s primerjalno analizo in ilustrativnimi prevodi Petrarkovih sonetov trudil dokazati, da je Prešeren Petrarko „sam pripoznal” za svojega ucitelja, vendar „bolj po obliki kakor po duhu", tako da mu ,posnemanje svojega ucenika [...] nikakor ni kratilo in slabilo lastne individualnosti”. Prim. še SLODNJAKa (1984: 43-44, 260-267) in PATERnuja (1994: 88-99). 
so že nakazali, da je Prešeren Petrarkov Canzoniere s petrarkizmom vred sprejemal dialoško in tekmovalno. Tako v Ljubeznjenih sonetih, Sonetnem vencu in ,povenčnih sonetih" kakor tudi v Gazelah in Krstu pri Savici sta mu prišla prav kot oblikovno dognana, retorična in učena pesniška dikcija, ki podpira romantični načrt kultiviranja domače književnosti in ji pomaga loviti korak z drugimi narodnimi klasikami. Poleg tega sta pesniku omogočila ubesedovanje eksistencialno zahtevnega dojemanja ljubezenske želje, bolj ozkosrčnim bralcem in absolutističnim birokratom - oboji so se spotikali nad pesnikovim življenjem in ljubezenskimi „kvantami” - pa sta ponujala sprejemljivejšo, se pravi idealizirano in stilizirano sublimacijo erotike. Ne nazadnje je bil petrarkistični slogovni kodeks za romantični estetski pogled poetičen in očarljiv zaradi svoje historistične patine, nekakšnega spiritualnega erotizma in fiktivnosti. Prešeren je Petrarki ponekod na videz zvesto sledil in njegovo verzno-kitične oblikovanost, tematiko, figurativnost, kompozicijske klišeje, podobje in etološko perspektivo zgolj diskretno moderniziral in subjektiviziral, drugod pa se je od „učenika” (učitelja) že tudi ironično distanciral.

Izvirni in prevodni sonet se je na Slovenskem po letu 1818 (Janez VeselKoseski, Potažba) do Prešerna pojavljal bolj priložnostno; pesniki se pri tem niso sklicevali niti na izvore te oblike niti na njen poseben pomen (Pretnar 1993: 137). Prešeren pa je sonet kot literarno vrsto, ki izvira iz (neo)petrarkistične pesniške govorice, presadil $\mathrm{v}$ nastajajoči sistem slovenskega leposlovja tako, da ga je pospremil s samorefleksivnimi in parodičnimi ustvarjalnimi strategijami. V pesmi Kupido! ti in tvoja lepa starka (1831, nato v Poezijah, 1847) se je Prešernovo ustvarjalno sprejemanje petrarkističnega slogovnega kompleksa že izostrilo v polemično tematizacijo (prim. Paternu 1994: 89-90). Igrano jezljivi, anakreontsko frivolni ton in pogovorni, že kar frazeološki stilemi (npr. „Kupido! ti in tvoja lepa starka, / ne bota dalje me za nos vodila") so v parodičnem razglasju z ostanki petrarkističnega učenega mitološkega aparata, te pa sobesedilo že tako ali tako degradira. Sonet svojo pomensko zgradbo opira na zavest o razliki med pesniškim in biografskim jazom, še bolj pa na pesnikovo dojemanje ontološkega, etičnega in estetskega prepada med petrarkistično stilizacijo erotike - ta je skrajno polepotena, ukrojena po starih krojih izročila, psihično nestvarna - in nastopajočo meščansko stvarnostjo prve tretjine 19. stoletja; ta je namreč tudi na področju ljubezenskih razmerij priznavala predvsem ekonomijo, profit („plačilo”). Pesniški subjekt navidezno pristaja na prozaično družbeno resničnost svojega časa, na zakone kapitala in načelo užitka (,cel dan iz pravd koval bom rumenjake, / zvečer s prijatli praznil bom bokale”). Zato se z robatimi besedami odreka „tlaki”, in to v dveh njenih pomenih, estetsko-literarnem in erotičnem. Slovo daje tako služenju tradicionalnemu sonetnemu obrazcu kakor tudi obvezujočemu čaščenju ,gospe”, ki ga je zahteval ravno obrazec, podedovan od ,siromaka Petrarke".

Prešeren, ta „lirik z distance” (Avgust Žigon), je bil - kot kaže med drugim omenjeni zgled - schleglovec tudi zaradi izrazite in pesniško skrbno izdelane 
samorefleksivnosti. ${ }^{5} \mathrm{~V}$ svojih samorefleksivnih sonetih, napisanih v slovenščini in nemščini, se ni lotil samo svoje lastne vpetosti v neopetrarkistično tradicijo sonetopisja. Dotikal se je še mnogih drugih okoliščin, ki jih je občutil kot pomembne pri svojem pesniškem ustvarjanju. V sonete je vtkal satirično-ironične, parodične, elegično-sentimentalne in/ali humorne metapoetske komentarje. Nekateri med njimi so zadevali tudi pričakovano recepcijo njegovih Ljubeznjenih sonetov. Natančneje, merili so na razcep med obzorjem pričakovanj, s katerim so tedanji, narodnostno osveščeni kleriški in laični izobraženci jemali v roke Prešernova dela, in vsebinami oziroma formami, ki so jih ta v resnici prinašala. V besedilu Očetov naših imenitne dela (1831) se je Prešeren na primer z ironično skromnostjo odpovedal razsvetljensko-klasicističnemu in narodnoprebudnemu literarnemu programu. S tem je ironiziral tudi pričakovanje, da bo kot pesnik z retoričnim patosom opeval (psevdo)zgodovinske in epske snovi. V nasprotju z željami po epski in rodoljubni grandomaniji - čez nekaj let jim je začel uspešno streči njegov tedanji konkurent Koseski - se je sam odločil pisati ljubezenske pesmi. S samorefleksivnim sonetom je zagovarjal izbiro subjektivne, erotične tematike in srednje slogovne lege v ciklu Ljubeznjeni soneti. ${ }^{6}$

$\mathrm{Na}$ aporije, ki jih je že čez nekaj let prinesla stvarna recepcija njegovih ljubezenskih sonetov, je Prešeren v samorefleksivnih sonetih reagiral bolj prizadeto in resnobno. Potem ko je dal v prilogi k časopisu Illyrisches Blatt (22. februarja 1834) natisniti svoj Sonetni venec s posvetilnim akrostihom Primicovi Juliji, je prišlo do komunikacijskega nesporazuma in škandala. Pesnik se je, na veliko nejevoljo rodbine Primicovih, v vencu drzno poigral z ,normo intimnosti” (Dąbrowska-Partyka 1994), ključno za oblikovanje moderne meščanske civilizacije. To normo je večkrat transgresivno prekršil: dvoumno je mešal javno poetično izrekanje in strogo zasebno ljubezensko nagovarjanje bogate in ugledne meščanke Primicove Julije, katere ime je žarelo iz črk akrostiha. Da bi popravil vtis, ki je nastal po objavi Sonetnega venca, se je Prešeren v t. i. povenčnih sonetih trudil naknadno razložiti, kakšni naj bi bili resnični sporočilni nameni tega ljubezenskega cikla. V povenčnih sonetih torej „brani in pojasnjuje svoje pojmovanje ljubezni in poezije” ter „združuje s presenetljivo izvirnostjo in zmagovito duhovitostjo izpovedne in literarnoteoretične elemente" (Slodnjak 1984: 50). Sonetnega samopremisleka je deležna še konkretizacija ljubezenskega čustva v pesniškem prispodabljanju (Pretnar 1993: 146). S pretanjenimi metaforami je pesnik skušal ponazoriti, da je njegova erotika v Sonetnem vencu zgolj estetska, poetizirana, sublimirana v domišljijo, da je

5 Tudi PATERNu (1994: 48) pri njem poudarja „uzavešcenost umetnostnih postopkov” ali t.i. „Kunstbesonnenheit”.

${ }^{6}$ Prešeren je s tem aktualiziral staro poetiško hierarhijo. Dante je v spisu De vulgari eloquentia (1305) sonet, približno sedemdeset let po nastanku, uvrstil nižje kot obsežnejše pesniške vrste, na primer canzone; slednje naj bi po njegovem vodile k razkošnejšim retoricnim figuram in najvišji slogovni ravni, sonet pa je bil zaradi svoje kratkosti - kljub prestižu v njem obravnavanih tem - elokucijsko preprostejši (prim. SPILLER 1992: 8-9).

Studia Slavica Hung. 45, 2000 
skratka čista; zato za pesniško nagovorjenko in njene sorodnike ni mogla biti družabno nevarna. V sonetu Na jasnem nebi mila luna sveti takšno misel izrazi z antitezo med dvema vrstama svetlobe - silovitim neposrednim žarom sonca v dnevnem življenju in lepotno, milo, čudežno, indirektno in nočno-sanjsko svečavo lune. $\mathrm{Ni}$ znal molitve žlahtnič trde glave pa skicira legendo o govorniško okornem, a iskrenem molivcu in jo uporabi kot parabolo za svoje pesnjenje. Prešernova samorefleksivna metaforika, ki kontrastira moči dveh svetlob in kaže na posvetno „nepragmatičnost” molitve, je torej skušala med bralci izostriti čut za razliko med ilokucijsko silo pravega, direktnega dvorjenja na eni strani in fiktivno, estetsko posredovano ter depragmatizirano govorico sonetnega ljubezenskega čaščenja na drugi strani. Zato sta lahko ta dva samorefleksivna soneta v nastajajočem avtonomnem sistemu umetnosti na Slovenskem delovala tudi samoregulacijsko: pesnik je namreč s pesniškimi besedili avtopoetično sam pomagal oblikovati podlage za estetsko in polivalenčno konvencijo, ki naj bi določali pisanje, branje in vrednotenje (njegove) lepe besede (prim. Schmidt 1980: 92-95, 104-107, 140-141; Juvan 1994: 284-288).

Prešeren je s samorefleksivnimi soneti opravičil in podkrepil še marsikakšno ustvarjalno izbiro, denimo to, da je objavljal tudi v nemščini. V nemškem sonetu Warum sie, wert, dass Sänger alle Zungen (1834) je v ta namen povlekel iskrivo analogijo med sociolingvistično jezikovno hierarhijo, po kateri je bila slovenščina na Kranjskem podrejena nemščini, in trubadursko služnostjo opevani dami; v pesmi Sängers Klage (1833) pa je svoje občutje osamljenosti in utesnjenosti med nezaupljivimi ali celo sovražno nastrojenimi sonarodnjaki aluzivno primerjal z Ovidovo usodo - izgnanstvo v (jezikovno) tujino je pri njem rodilo pretresljive umetnine. Samopremislek o pesništvu je pri delu še v nekaterih Prešernovih sonetih. Apel podobo na ogled postavi (1833, Poezije) se s parafrazo antičnega motiva in $\mathrm{z}$ eno izmed Prešernovih bistrih paronomazij satirično posmehuje omejenosti, kakršno si je pri vrednotenju njegove poezije privoščil znameniti lingvist Jernej Kopitar. V posvetilnem sonetu Matiju Čopu interpretira osebni in biografski smisel svoje pesnitve Krst pri Savici (1836, Poezije), v nemškem sonetu Nicht trägt an ihm des Dichtergeists Gepräge (1840) pa komentira razkorak med svojo neuspešno in neromantično empirično osebo in svojim ,pesniškim duhom”, tj. kontrast, ki že razdira stereotip romantičnega pesniškega genija.

Iz obravnavanih primerov je razvidno, da je sonetna samorefleksija Prešernu rabila predvsem za pesniško utiranje poti $\mathrm{k}$ ustrezni recepciji njegove poetike, jezika in domišljije. Pomenila je strategijo, s katero je - kot eden prvih ustvarjalnih akterjev v nastajajočem sistemu avtonomne besedne umetnosti v slovenščini - med domače bralce, razumnike, laične in posvetne avtoritete, cenzorje ter prve recenzente vcepljal zavest o posebnosti in izjemnosti pesniške govorice oziroma postopno oblikoval konvencije, po katerih se umetniško literaturo ustvarja in razumeva drugače od ostalih področij družbenega diskurza. Njegovo samorefleksivno sonetopisje je bilo namenjeno obračunavanju z literarnimi pričakovanji in družbe- 
nimi predsodki, nazorsko ozkosrčnostjo ali kritiško-cenzurnim zatiranjem, polemiki z narodno neosveščenostjo, razsvetljenskim utilitarizmom in literarnoestetskimi koncepcijami, ki so se Prešernu zdele zgrešene. Posvečalo se je še opravičevanju, razlagi in utemeljevanju pesnikovih lastnih (sonetističnih) estetskih vodil, tematskih in oblikovnih izbir, videnju svojega družbenega položaja. Ne samo soneti, ampak Prešernovo delo v celoti je zavzeto s samoopazovanjem in z (meta-) poetološkimi refleksijami. Spomniti se velja na Zabavljive napise, Gloso, Novo pisarijo, Orglarja, posamezna mesta iz Gazel, Pevca in Neiztrohnjeno srce.. To pravzaprav ne preseneča, saj so v romantični metafiziki lepota, poezija in avtonomna subjektivnost vrhovne vrednote (Wellek 1963: 196-197, 221; Kos 1980: 30-31, 38-39, 42-49). Samorefleksija pa pri Prešernu še nikjer ne pride do pravega soneta o sonetu.

Najbolj se mu je približal Sonetni venec (1834, Poezije), cikel besedil, ki velja za enciklopedično sintezo Prešernovega dotedanjega sonetopisja, za splet ljubezenske, narodne, pesniške in bivanjske tematike (Paternu 1994: 79-80). Sonetni venec vseskozi, posebej pa v uvodnem sonetu programsko razodeva, da je Prešeren konotativni potencial pesniških oblik obravnaval samorefleksivno. V tem primeru je zavest o svojih ustvarjalnih postopkih pokazal dokaj demonstrativno: „zunanja” oblika in njeno evokativno ime (venec), povzeta po poetoloških navodilih sienskega venca sonetov (Paternu 1994: 81-82), funkcionirata kot ikonični znak za „notranjeformalno" prepletanje poglavitnih tem in perspektiv prešernovskega sonetnega diskurza.

V pravilih sonetnega venca je pri delu avtopoetičnost, saj se pesnjenje razrašča iz strukturno-semantičnih semen enega besedila. Iz Prešernovega magistralnega 15. soneta ,zvira, vanjga se spet zlije pesem trikrat peta": iz enega soneta, ki je tudi sinopsis celote, se poraja besedilo besedil, $\mathrm{v}$ katerem kompozicijsko sosledje tem proizvaja še rekurzivnost ponovljivih katenskih verzov, tako da se začetek in konec spletanja skleneta $\mathrm{v}$ zaokrožen venec. Pesnik v kvartetah uvodnega soneta opisuje ta avtopoetični oblikovalni postopek. Njegova govorica pri tem s svojo številsko-geometrično evokacijo sonetne harmonije sozvanja s sonetom o sonetu, ki ga je kot dopolnilo k svojim predavanjem o tej obliki v letih 1803-4 napisal August Wilhelm Schlegel (Das Sonett). Pri Schleglu sonet nastopa kot govoreči jaz in nazorno, kot kakšen predavatelj, opiše, kako harmonični so njegovi vzorci rimanja, opozarja na „skriti čar”, ki ga nudi občutljivim pesnikom (,vzvišenost in polnost v tesnih mejah”, „čisto somerje nasprotij”) in polemizira s tistimi, ki so med t. i. sonetno vojno v njem videli zgolj igračo in kalup:

Zwei Reime heiss' ich viermal kehren wieder

Und stelle sie, geteilt, in gleiche Reihen,

Dass hier und dort zwei, eingefasst von zweien,

Im Doppelchore schweben auf und nieder.

Dann schlingt des Gleichlauts Kette durch zwei Glieder,

Sich freier wechselnd, jegliches von dreien. 
In solcher Ordnung, solcher Zahl gedeihen

Die zartesten und stolzesten der Lieder.

Den werd' ich nie mit meinen Zeilen kränzen,

Dem eitle Spielerei mein Wesen dünkt,

Und Eigensinn die künstlichen Gesetze.

Doch, wem in mir geheimer Zauber winkt,

Dem leih' ich Hoheit, Füll in engen Grenzen,

Und reines Ebenmass der Gegensätze.

(nav. po Mönch 1955: 15, 51.)

Pri Prešernu pa v nasprotju s Schleglom spregovarja pesnik, ne sonet:

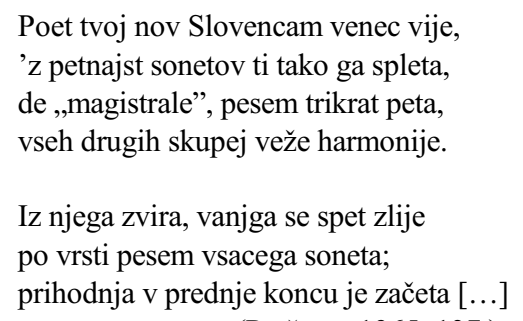

V figurativni igri svojilno-dajalniških kategorij (tvoj, Slovencam, ti), ki Prešernovo sonetno izjavljanje vodi k prestopanju meje med javnim in zasebnim sporočanjem, se snuje tudi avtoreferencialnost: sonetni venec se $\mathrm{v}$ svojem uvodnem delu s figurativnimi izrazili sam opisuje. Pesniški subjekt kot da sproti spremlja pisanje ,poeta”, se pravi samega sebe. Razlaga svojo individualno uresničitev generične pesniške oblike. Iz zavesti o njeni novosti na Slovenskem predstavlja njena zgradbena načela. $Z$ opisa forme preide na interpretiranje njenega simbolnega pomena, podobno kot Schlegel, a tako, da vsebinski korelat forme mnogo tesneje in pesniško bolj pretanjeno naveže na svojo individualnost:

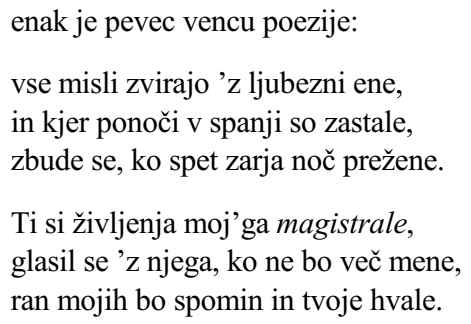

Terceti uvodnega soneta torej formi celotnega venca vnaprej pripišeta poudarjeno simbolno konotativnost: metaforično identificirata pesnika in njegove misli z njegovim sonetnim vencem, ljubljeno naslovljenko pa $\mathrm{z}$ magistralom. S tem Prešernovo življenje preobražata $\mathrm{v}$ en sam velik pesniški tekst. Uvodni sonet venca je kompleksna metafora za pesnikovo ljubezen in vero v krožni, neskončni čas 
poezije, ki presega linearnost biografije. Na teoretski ravni se v tem besedilu razodeva podoba romantične tekstualnosti: med subjektom in besedilom pri Prešernu ni nobenega odkritega konflikta, pač pa ju organsko veže niz ekvivalenc, ki besedilo harmonizirajo s pesniškim jazom.

Boris Paternu je v interpretaciji Sonetnega venca ugotovil, da je „mit poezije in njene orfejske moči” temelj, „na katerem sloni harmonična struktura pesnitve” in ki ,iz ozadja spreminja ljubezensko v poetološko pesnitev”, tako da ga imamo lahko „,za nekakšnega glavnega junaka pesnitve, čeprav je zanj navzven razglašena Julija”. Ta poudarek, ki izhaja tudi iz ugotovitve, da ,poetološka tema kontinuirano živi skozi vse sonete in poleg tega zavzema obe odlični mesti ciklusa, uvodno in sklepno" (Paternu 1994: 85), se ujema z vidiki, ki so se pričujočemu razpravljanju odprli ob razlagi prvega soneta. Ne samo uvodni sonet, ampak venec v celoti je resnično posvečen zlasti pesnikovi samorefleksiji. Rdeča nit avtotematizma se tke skozi prav vse sonete: lirski subjekt upesnjuje poezijo kot spominsko sled ljubezenske biografije, jo umešča v književno in družbeno-nravstveno izročilo ter utopične projekcije (2. sonet), vztrajno pojasnjuje njeno izpovednost in petrarkistično sentimentalni ton (3., 4., 5. in 11. sonet), elegično označuje družbenojezikovne, kulturne in narodnozgodovinske okoliščine, ki so onemogočale razcvet slovenske poezije (6., 7. in 8 . sonet) ter ob orfičnem mitu utopično zagovarja narodnopovezovalno in kultivacijsko vlogo (svoje) poezije (7. sonet), kar ob Ifigenijinem mitu veže še $z$ osebno željo po bivanjski in ustvarjalni odrešitvi, ki naj bi jo prinesla moč ljubljene ženske, pa tudi s strategijo, da bi fikcijsko sporočanje pridobilo njeno stvarno naklonjenost (9., 12., 13., 14. in 15. sonet). Ljubezenska in domovinska tematika sta tako podrejeni dominanti pesniške samorefleksije; edina stalna izotopija sonetov v vencu je ravno pomensko polje poezije.

Zastopa ga zlasti metaforika cvetja, rož in rastja ter topika Parnasa in Orfeja. Metaforiko cvetja po eni strani poraja že golo žanrsko ime kompozicije, tj. sonetni venec, po drugi strani pa se $\mathrm{v}$ njej razodevata dve potezi romantične poetološke miselnosti: organska povezanost narave in človeka, estetska vzporednost med njima (Wellek 1963: 160-198, 220; Kos 1980: 30). Podoba cvetja - njegova bledost, redkost ali bohotnost - je v skladu s takšno logiko odvisna od podlag v subjektu ali narodu, iz katerih rožice organsko rastejo in ju izražajo, nič manj pa na cvetje ne vplivajo atmosferske okoliščine, ki reprezentirajo Drugega, in sicer bodisi nemile zgodovinske sile bodisi sončno svetlobo idealne nagovorjenke, Julije.

Vrh Sonetnega venca so pesmi, v katerih je izvor elegično-sentimentalnega značaja Prešernove poezije (,mokrocveteče rožce poezije”) razložen z zgoščenimi in metaforiziranimi pripovedmi o tem, kako skromna in nerazvita je bila slovenska lepa književnost. Razloge za to pretirano žalostno sliko narodove kulturne preteklosti odkriva Prešeren v tragični politični zgodovini. Pesniški subjekt skuša zgodovino Slovencev, ki jo je modeliral z elegično pripovedjo, utopično odrešiti. V sedmem sonetu (svoje) pesniško poslanstvo upodobi na tlorisu mita o Orfeju. Mitsko predlogo je priklical $\mathrm{z}$ aluzivno parafrazo in jo preinterpetiral $\mathrm{v}$ duhu romantične 
narodne ideje: poeziji in pesniku pripisuje narodnozdruževalno moč in zmožnost za kultiviranje barbarstva, ki še ni spoznalo lepote avtonomne Poezije. Fantazma tega soneta je, da naj bi poezija kljub svoji družbeni nemoči, nekoristnosti in obrobnosti postala tista realna sila, ki bi vsaj v sferi kulture, umetnosti in literarnega jezika zmogla združiti in konstituirati narodno občestvo, če to - iz zgodovinskih razlogov in zaradi nenaklonjenih sodobnih političnih razmer - svoje identitete ne bi moglo utemeljiti kako drugače, denimo ekonomsko ali državno. Josip Stritar je z esejem o Prešernu ta romantični ideologem že leta 1866 odločilno vgradil v slovenski literarni kanon in nacionalno ,mitologijo”, po zaslugi teoretika Dušana Pirjevca pa je čez približno sto let postal znan kot ,prešernovska struktura”.

Sonetni venec je po kanonizaciji Prešernovega opusa - ta se je postopno dovršila v zadnji tretjini 19. stoletja - vplival na slovensko pesniško izročilo na dva načina, ki se med seboj prežemata. Prvič, postal je zakladnica podob, krilatic, tropov in etičnih perspektiv, organiziranih okrog značilnega prepleta individualnih in družbenih fantazem, na primer „mita” odrešilne, duhovno soustvarjajoče ljubezni, elegičnega pripovedovanja narodove zgodovine in orfične vloge poezije. Drugič, postavil je kriterije zahtevnega, ,visokega” umetniškega oblikovanja, utrdil prestiž sonetne oblike in uveljavil literarnovrstni prototip sonetnega venca. Do danes je nastalo prek 50 sonetnih vencev, med avtorji pa so Ivan Pregelj, Matej Bor, France Balantič, Mitja Šarabon, France Kosmač, Vladimir Kos, Jože Šmit, Janez Menart, Ljubka Šorli, Veno Taufer, Boris A. Novak in Jurij Kovič. Obliko sonetnega venca so slovenski pesniki pod vplivom neuresničenih Balantičevih načrtov celo potencirali v sonetni venec sonetnih vencev; ta, v evropskih literaturah izjemna oblika je po Mitji Šarabonu (njegov Sonetni venec sonetnih vencev je bil napisan 1945, natisnjen pa šele 1971) prinesla okrog deset realizacij, največ izpod peresa Valentina Cundriča (prim. Bregant 1997). Sonet se je po Prešernu v slovenski liriki uveljavil kot najpogostejša in zvečine tudi najbolj prestižna stalna oblika; v 1980. letih se je razpasla pravcata ,sonetomanija” (Pretnar 1984) in se še do danes ni umirila (prim. Dolgan 1999). Poleg Krsta pri Savici, Lepe Vide, Pevca in Sonetov nesreče je Sonetni venec postal tudi eno ključnih, najbolj citiranih Prešernovih besedil.

Prešeren pa je na svoje pesniške potomce vplival tudi s svojo sonetno samorefleksijo in jih spodbujal $\mathrm{k}$ dialogu. Za konec naj samo skiciram poti samorefleksivnih sonetov $\mathrm{v} 20$. stoletju, in sicer $\mathrm{v}$ tokovih modernizma in postmodernizma. V nasprotju $\mathrm{z}$ estetskim organicizmom Prešernove romantike je modernizem čedalje bolj širil razcep med sonetnim besedilom (obliko) in izpovedujočim se subjektom (Srečko Kosovel, Pred zimo, ok. 1925, Veno Taufer, Grad strahov, 1969). Visoki modernizem Nika Grafenauerja je nazadnje subjekt iz pesmi celo izbrisal, tako da je ostal le še „na nič odtisnjen bakrorez soneta” kot emblem poetične igre jezikovnih struktur in čiste estetske forme (Glasovi v gladki bisernici svita, 1975). Božo Vodušek, začetnik moderne lirike med obema svetovnima vojnama, je v sonetih izzivalno depoetiziral romantično in sentimentalno lirsko izročilo, kakršnega je zasnoval Prešeren. $Z$ veliko mero načrtne prozaizacije in ciniz- 
ma je romantične motive, metafore in stil odprl izkušnji modernega „odčaranega sveta" (Roža in plevel, 1935-36). Taufer kot eden vidnejših naslednikov Voduškove poetike po drugi svetovni vojni je v samorefleksivnem sonetu Orfej (1962) parodično in ironično obračunal kar z estetsko-ideološkim kompleksom ,prešernovske strukture", katere izvor je, kot smo videli, v Sonetnem vencu. Prešernov mit pesnika kot trpečega junaka, ki s svojo umetniško ustvarjalnostjo plemeniti in združuje svoj narod, je Taufer sprevrnil v tragikomično sliko pevca brez najmanjše karizme in daru. Po takšnem razvoju samorefleksivnih sonetov v modernizmu je Milan Jesih napisal zbirko Soneti (1989), ki velja za najboljši primer postmodernizma v slovenski liriki. Na njenih zadnjih straneh se nahaja nekaj avtotematskih besedil, ki razodevajo pomembne spremembe v dojemanju soneta. Gre za simulakersko rekonstrukcijo lirske osebe in subjektivnega razpoloženja, obuditev tradicionalnih in prepoznavnih pesniških motivov (ljubezenskih, pivskih, naravnih), citatno poigravanje s Prešernovim slogom, metafikcijske preskoke med resničnost$\mathrm{mi}$ in fikcijami itn. V primerjavi s Prešernovo romantično glorifikacijo in tragizacijo pesnika pa je tudi Jesih s pietetno samoironijo naslikal veliko skromnejšo podobo ustvarjalca: to je le še moderni „rokodelec”, ki se trudi, da bi se mu pesem posrečila. Nanjo pa ni usodno in eksistencialno navezan. Pesnjenje mu je le ena izmed enakovrednih tekstualnih praks. Zdi se, da je med mlado pesniško generacijo, ki je nastopila sredi 90. let, ironična kritika in samodestrukcija romantičnega pesniškega poslanstva, kakršne sta se lotila modernizem in postmodernizem, stopila v ozadje in da se vnovič krepi vera v presežno moč lirske govorice.

\section{Literatura}

Sandra L. Bermann (1985). The sonnet: Repetition with a difference. Proceedings of the 10th Congress of the ICLA. New York. 7-11.

Mihael Bregant (1997). Fenomen sonetnih vencev sonetnih vencev. Sonet in sonetni venec. Ur. B. Paternu.. Ljubljana: Filozofska fakulteta. 437-448.

Maria DĄBROWSKA-PARTYKA (1994). Norma intimiteta kao modalni okvir teksta. Individualni in generacijski ustvarjalni ritmi v slovenskem jeziku, književnosti in kulturi. Ur. M. Juvan, T. Sajovic. Ljubljana: Znanstveni inštitut Filozofske fakultete, Oddelek za slovanske jezike in književnosti. 387-396.

Marjan Dolgan (1999). Bibliografija pomembnejših slovenskih sonetnih pesniških zbirk. Primerjalna književnost 22/1. 91-120.

John FULLER (1978). The sonnet. London: Methuen.

Niko Grafenauer (1977). Pesmi. Ljubljana: DZS.

Erika GREBER (1994). Wortwebstühle oder: Die kombinatorische Textur des Sonetts. Thesen zu einer neuen Gattungskonzeption. Zeichen zwischen Klartext und Arabeske. Ur. S. Kotzinger, G. Rippl. Amsterdam-Atlanta: Rodopi. 57-80.

Milan JeSIH (1989). Soneti. Celovec: Wieser.

François Jost (1975). Modes et modulations d'un genre: Le sonnet. Proceedings of the 6th Congress of the ICLA. Stuttgart. 65-78.

Marko JuVAN (1994). Slovenski Parnasi in Eliziji: Literarni kanon in njegove uprizoritve. Individualni in generacijski ustvarjalni ritmi (gl. Dąbrowska-Partyka 1994). 277-315.

Marko Juvan (1997). Domači Parnas v narekovajih: Parodija in slovenska književnost. Ljubljana: LUD Literatura.

Studia Slavica Hung. 45, 2000 
Janko Kos (1980). Romantika. Ljubljana: DZS.

Matevž Kos (1990). Sonet kot forma prebolevanja modernosti. Literatura 2/7. 111-120.

Srečko Kosovel (1974). Zbrano delo 2. Ur. A. Ocvirk. Ljubljana: DZS.

Milena KoŽUH (1979). Sonet v poeziji med obema vojnama: Njegova pogostnost in oblikovne posebnosti. Slavistična revija 27/2. 207-213.

Juraj MARTINOviĆ (1988). Dva tipa soneta i dva vida njegove recepcije. Sodobni slovenski jezik, književnost in kultura. Ur. B. Paternu, F. Jakopin. Ljubljana: Oddelek za slovanske jezike in književnosti, Znanstveni inštitut Filozofske fakultete. 63-80.

Magdalena Medarić (1993). Ono što upućuje na sebe - prilog terminologiji autoreferencijalnosti. Intertekstualnost \& autoreferencijalnost. Ur. D. Oraić-Tolić, V. Žmegač.. Zagreb: Zavod za znanost o književnosti. 97-104.

Walter MÖNCH (1955): Das Sonett: Gestalt und Geschichte. Heidelberg: Kerle Verlag.

Boris A. NovaK (1991). Oblike sveta: Pesmarica pesniških oblik. Ljubljana: Mladika.

Boris A. NovAK (1995). Oblika, ljubezen jezika: Recepcija romanskih pesniških oblik v slovenski poeziji. Maribor: Obzorja.

Boris PATERNU (1976). Izhodišča Prešernovega sonetizma. Slavistična revija 24/1. 39-55.

Boris PATERNU (1990). Jesih v klasiki. 26. Seminar slovenskega jezika, literature in kulture. Ur. T. Pretnar, D. Pocaj Rus. Ljubljana: Filozofska fakulteta. 89-100.

Boris PATERnU (1994). France Prešeren: 1800-1849. Bled - Ljubljana: Dr. A. Kovač, ZIFF.

Svetozar PETROvić, ur. (1991). Stih $i$ žanr/Verse and genre. Novi Sad: Vojvodjanska akademija nauka i umetnosti.

Jože PoGAČNIK (1997). Sonet (pojmovna določitev). Sonet in sonetni venec. Ur. B. Paternu. Ljubljana: Filozofska fakulteta. 419-428.

France PreŠEREN (1965). Zbrano delo 1. Ur. J. Kos. Ljubljana: DZS.

Tone PRETNAR (1984). Med sonetomanijo in ljudskostjo v slovenskem pesništvu zdajšnjega časa. 3. Srečanje slovenskih pesnikov. Kranj. 55-62.

Tone Pretnar (1993). Romantično tridesetletje (1818-1848) - vir slovenskega sonetizma. Slowiańska metryka porównawcza: V. Sonet. Ur. L. Pszczolowska, D. Urbańska. Warszava: IBL. 133161.

Hans-Jürgen SCHLÜTTER (1979). Sonett. Stuttgart: Metzler.

Siegfried J. SCHMIDT (1980). Grundriss der empirischen Literaturwissenschaft. Teilband 1. Braunschweig-Wiesbaden: Vieweg.

Anton SlodNJAK (1984). France Prešeren. Ur. F. Bernik. Ljubljana: Slovenska matica.

Michael R. G. SPILlER (1992). The development of the sonnet: An introduction. London-New York: Routledge.

Josip StRITAR (1969). Prešeren. Izbrano delo. Ur. J. Vidmar. Ljubljana: Mladinska knjiga. 7-48.

Veno TAufer (1994). Nihanje molka: Izbrane pesmi. Ur. M. Kos. Ljubljana: Mladinska knjiga.

Božo VoduŠEK (1980). Pesmi. Ur. J. Kos. Ljubljana: Mladinska knjiga.

René WeLleK (1963). The concepts of criticism. New Haven - London: Yale Univ. Press. 